\title{
Reducing nitrogen oxide emissions in boilers at moistening of blowing air in heat recovery systems
}

\author{
Raisa Navrodska $^{1}$, Nataliia Fialko ${ }^{1, *}$, Georgii Presich $^{1}$, Georgii Gnedash ${ }^{1}$, Sergii Alioshko ${ }^{1}$, \\ and Svitlana Shevcuk ${ }^{1}$ \\ ${ }^{1}$ The Department of Thermophysics of Energy Efficient Heat Technologies, Institute of Engineering \\ Thermophysics of National Academy of Sciences of Ukraine, Kyiv, Ukraine
}

\begin{abstract}
Considered indicators of reducing harmful emissions into the environment by gas-fired water-heating and steam boilers of the municipal heat-power engineering, which are equipped with heat-recovery systems of boiler exhaust-gases. The results of studies on the relative decrease of emissions of nitrogen oxides and other harmful substances generated during fuel combustion in boilers when used for boilers complex heat-recovery plants for heating heat-network water and water for a chemical water-purification system of a boiler plant, as well as for heating and humidifying combustion air are presented. It is shown that the use of such complex heat-recovery systems, due to the useful heat of exhaust-gases from boilers, provides a reduction in fuel consumption and, consequently, the volumes of harmful emissions generated during its combustion, by $8-12 \%$, depending on the mode of operation of boilers during the heating period. The efficiency of using combustion-air humidifying in these installations to decrease the level of formation of nitrogen oxides in the combustion area of boilers is considered. It is also shown that the use of these systems provides a decrease emissions of nitrogen oxides to the environment by up to $60 \%$ by reducing the combustion temperature in the combustion area at moisture introduction with the combustion air and, as a result, suppression of formation these oxides during fuel combustion in boilers. The substantiation of the accuracy of the obtained calculated values of the levels of relative decrease of emissions of nitrogen oxides with the moisture introduction into the boiler by comparing them with experimental data is given. Comparative of the results shows a good agreement between the calculated and experimental data.
\end{abstract}

\section{Introduction}

A significant share in pollution of environment is made by fuel-fired installations of various purposes. Among them, heat-generating boiler plants are especially distinguished, they are intended for heat supply of residential and municipal facilities. The reduction of emissions

*Corresponding author: nmfialko@ukr.net 
to the environment by such installations is currently being solved through the use of heatrecovery technologies that decrease fuel consumption and, as a result, reduce harmful emissions generated during its combustion. The greatest thermal and ecological effect is achieved in this case at the use of complex heat-recovery systems [1-6] in which deep cooling of the exhaust-gases of boiler plants is realized (below the dew point of the water vapor contained in them).

\section{Prerequisites and means for solving the problem}

This paper is devoted to research on the effect-use of complex heat-recovery systems for gas-fired boilers designed to heat and humidity combustion air and to heat cold water for chemical water-purification system. These systems are characterized the additional environmental effect associated with a decrease in the formation of nitrogen oxides during fuel combustion in boilers. In these systems, the heating of combustion air and water of the chemical water-purification system (CWP) is intended to increase the fuel efficiency in the boiler, and its humidifying is reduced the formation of nitrogen oxides by lowering the combustion temperature in the boiler [7-9].

The aim of the study is to assess the levels of decrease of nitrogen oxide emissions in water-heating and steam gas-fired boilers in different modes of their operation at humidifying the combustion air.

\section{Solution of the examined problem}

In fig. 1 shows a schematic circuit of a heat-recovery plant with complex use of heat of recovery for heating and humidifying the combustion air and heating cold water of CWP system.

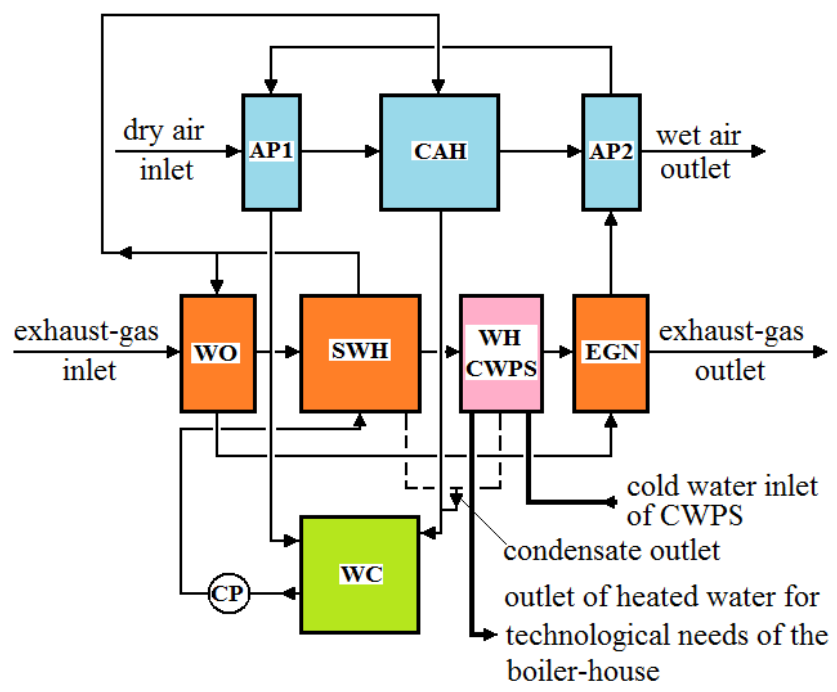

Fig. 1. Schematic circuit of a complex heat-recovery system with heating and humidifying the combustion air and heating the cold water of the chemical water-purification system: AP1 - first air preheater; $\mathrm{CAH}$ - contact air heater; AP2 - second air preheater; $\mathrm{WO}$ - water-overheater; SWH - surface water heater; WH CWPS - water heater of chemical water-purification system; $\mathrm{EGH}$ - exhaust-gas heater; $\mathrm{WC}$ - water collector; $\mathrm{CP}$ - the centrifugal pump. 
The heat-recovery installation works as following way. Exhaust-gases of the boiler with high moisture content are first cooled in the water-overheater WO, and then come to the surface water heater SWH where the cooling takes place below the dew point of the water vapor contained in these gases, that is, under conditions of condensation of steam from the exhaust-gases. Further cooling of the exhaust-gases with the implementation of the condensation regime is carried out in a water heater of the chemical water purification system WH CWPS. In condensing mode of operation of the water heaters WO and WH CWPS, the heat of condensation of water vapor contained in the exhaust-gases is used. After these water heaters, the exhaust-gases are dried in the exhaust-gas heater EGH to a level that avoids the formation of condensate in the exhaust ducts of the boiler plant [10], and leave the heat-recovery system.

Water from the water collector WC is taken by the pump and first pumped through the SWH, where it heats up, and then the circulation circuit splits. Part of the water enters the contact air heater $\mathrm{CAH}$, where it flows through the heat exchange surface, is cooled with partial evaporation and enters the WC. The rest of the water passes through WO, EGH, second air preheater AP2 and first air preheater AP1, being cooled successively, and also enters the WC. Then the cycle repeats.

Cold dry air outside the boiler house first enters the first air preheater AP1, where it is heated, then sent to the contact air heater $\mathrm{CAH}$, where it is heated and humidified, and through the second air preheater the AP2 is removed from the heat recovery system. Then goes into the air duct and enters the gas burner device the boiler.

An increase in air temperature provides a corresponding reduction in fuel consumption, and the humidifying of this air helps to decrease the formation of nitrogen oxides by lowering the combustion temperature by using part of the thermal potential of the flame to heat the introduced moisture.

Studies of the thermal and environmental performance of the heat-recovery installation were carried out at the load of the water-heating boiler in accordance with the heat boiler schedule shown in fig. 2, and for the steam boiler in two modes of operation, namely: $100 \%$ and $50 \%$. The environment air temperature $t_{e}$ for heating and humidifying in a heat-recovery system during the heating period was taken for two types of boilers in accordance with fig. 2

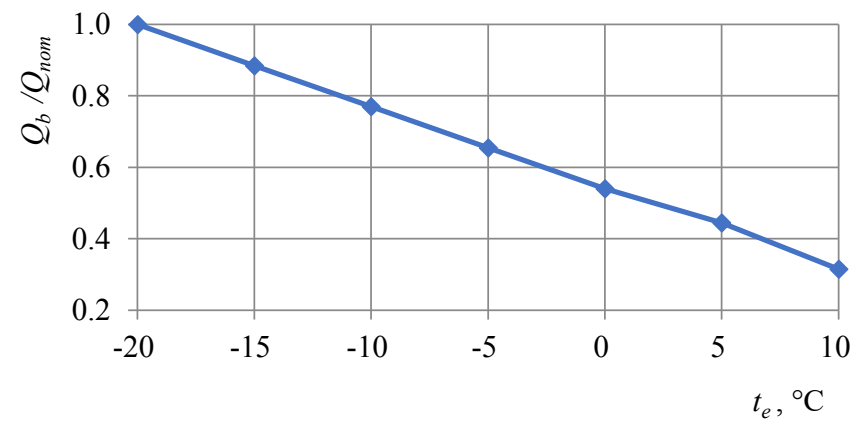

Fig. 2. Dependence of the load of the water-heating boiler on the environment temperature.

Thermal calculations of the elements of the complex heat-recovery system to determine the levels of fuel consumption reduction were performed according to well-known methods [11] using the calculated experimental dependencies obtained at the Institute of Technical Thermophysics of the National Academy of Sciences of Ukraine [12] in condensation modes. 
The volumes of $\mathrm{NO}_{\mathrm{x}}$ reduction were dependent on the water-fuel ratio $\beta$ in the boiler furnace according to the data of [9]. Namely, the relative decrease in nitrogen oxides in combustion products due to the humidification of the blown air was calculated by formulas:

$$
\begin{aligned}
& \Delta C_{\mathrm{NOX}}=1-\left(0,947 \cdot e^{-0,995 \beta}+0,066\right) \\
& \beta=G_{w} / G_{n g},
\end{aligned}
$$

where $\beta$ is water-fuel ratio, $\mathrm{kg} / \mathrm{kg} ; G_{n g}, G_{w}$ - mass flows of natural gas and moisture introduced into the boiler furnace with combustion air.

\section{Results and discussion}

The calculated data of the decrease of harmful emissions $\Delta C_{f}$ into the environment due to the reduction of fuel consumption to the boiler when using the complex heat-recovery system under consideration for the two types of boilers are shown in Fig. 3.

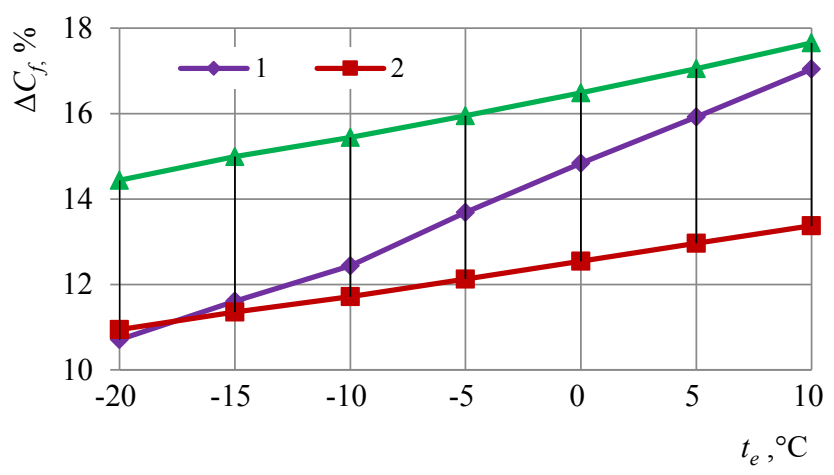

Fig. 3. The change from the environment temperature $t_{e}$ relative levels of decreasing the formation of harmful emissions in the boiler $\Delta C_{f}$ for water-heating and steam boilers when using the proposed heat-recovery system, ensuring a reduction in fuel consumption: 1 - water-heating boiler with a load in accordance with the heat schedule of Fig.2; 2 and 3 - steam boiler at a load of 100 and 50\%, respectively.

The results obtained indicate that the use of the heat-recovery system with the complex use of recycled heat provides for the considered boilers the significant decrease in the formation of harmful emissions in accordance with a reduction in fuel consumption. Namely: the value of $\Delta C_{f} \mathrm{f}$ is $10.8-16.6 \%$ for a water-heating boiler, and $11.1-17.5 \%$ for a steam boiler, depending on the operation modes of the boilers.

The results of studies on the decrease of the formation of nitrogen oxides $\Delta C_{\mathrm{NOx}}$ are shown in Fig. 4.

As can be seen from the obtained results, when using the proposed complex system for a water-heating boiler, there is a relative decrease in $\Delta C_{\mathrm{NOx}}$ of the formation of nitrogen oxides, from $22 \%$ to $63 \%$ depending on the mode of operation of the boiler in accordance with the environment temperature $t_{e}$. In this case, the maximum values of $\Delta C_{\mathrm{NOx}}$ correspond to the highest temperature of the heating period. With a higher air temperature at the inlet to the heat-recovery system, and therefore in the contact air heater $\mathrm{CAH}$, its consumption is reduced in accordance with the mode of operation of the boiler. This makes it possible to humidify the combustion air to a higher level and, accordingly, increase the water-fuel ratio 
$\beta$ for fuel combustion. This ensures a decrease in the formation of nitrogen oxides in combustion area of boiler.

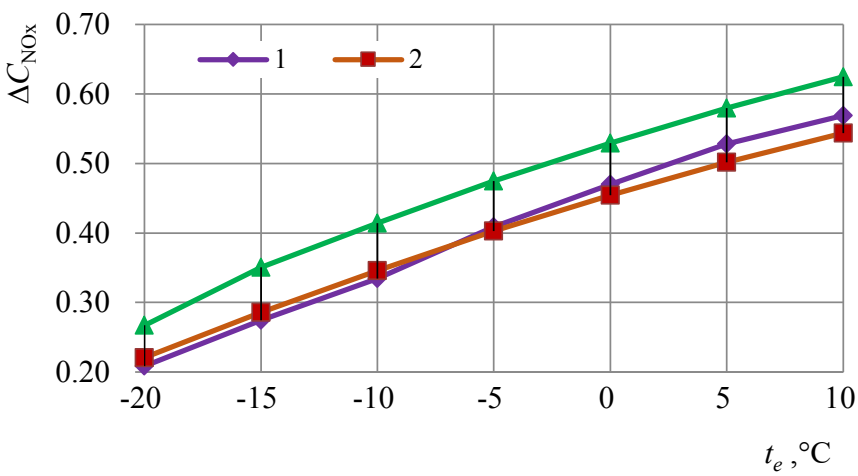

Fig. 4. The change at the application of the complex heat-recovery system of the relative decrease of nitrogen oxides $\Delta C_{\mathrm{NOx}}$ in the combustion area, depending on the environment temperature $t_{e}$ for water-heating and steam boilers in different modes of their operation at: 1 - water-heating boiler with a load in accordance with the heat schedule of Fig.2; 2 and 3 - steam boiler at a load of 100 and $50 \%$, respectively.

The same tendency is observed for the steam boiler, that is, the $\Delta C_{\mathrm{NOx}}$ values also depend on the mode of its operation and the input temperature of the heated air. At the same time, a greater decrease in the $\Delta C_{\mathrm{NO}}$ ratio corresponds to $50 \%$ of the boiler load, which is associated with a decrease in the air consumption for combustion. So with this load, the relative levels of reduction of the formation of nitrogen oxides $\Delta C_{\mathrm{NO}}$ vary from $27 \%$ to $63 \%$, and under a load of $100 \%$ - only from $21 \%$ to $54 \%$.

The proposed heat-recovery system is applied in the boiler house of PSC "KYIVENERGO" (Kyiv, Ukraine) (see fig. 5) for the steam boiler (type E-1/9) with a thermal capacity of $0.63 \mathrm{MW}$.

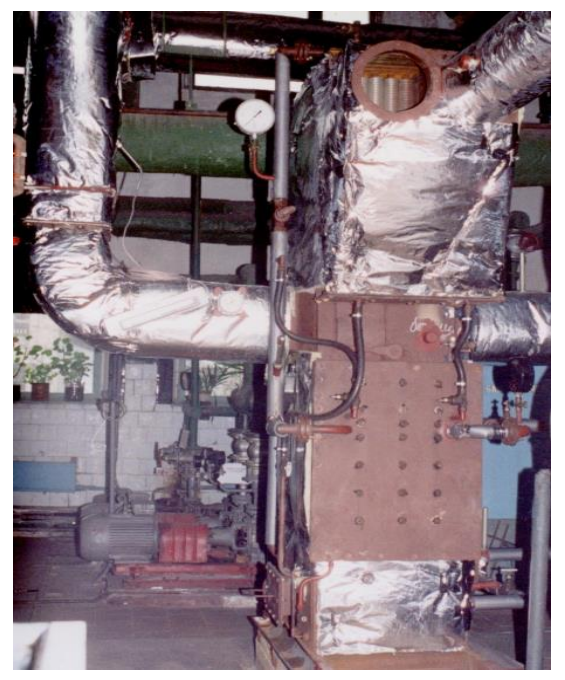

Fig. 5. Complex heat-recovery installation with heating and humidification of combustion air in the boiler house of PSC "KYIVENERGO” (Kyiv, Ukraine). 
To assess the accuracy of the calculations obtained when determining the values of the decrease of emissions of nitrogen oxides $C_{\mathrm{NOx}}$ with the introduction of moisture from the combustion air into the boiler furnace, a comparison was made of these calculations and experiments. The corresponding results are presented in fig.6.

The experimental values near curve 5 of fig. 6 correspond to personal measurements of the $\mathrm{NO}_{\mathrm{x}}$ content in the exhaust-gases at the outlet from the complex heat-recovery system, as well as the results of other researchers [9]. The calculated data for the decrease of $\mathrm{NO}_{\mathrm{x}}$ are determined using formula (1). Comparative of the results shows a good agreement between the calculated and experimental data.

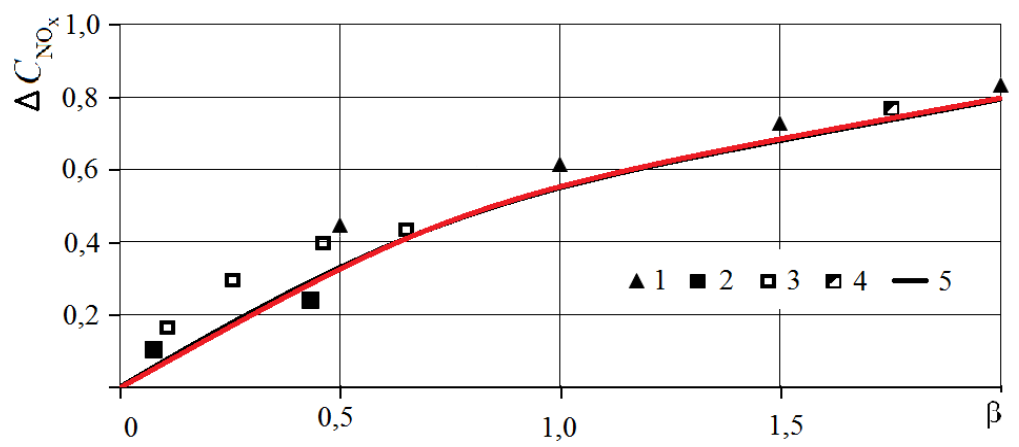

Fig. 6. Comparative of calculated and experimental data of the relative $\Delta C_{\text {NOx }}$ concentration in the exhaust-gases from the boiler with air humidification depending on the water-fuel ratio $\beta: 1,2$, 3 - experimental data of other researchers [9]; 4 - experimental data of personal tests; 5 - theoretical curve.

\section{Conclusions}

The results of the conducted studies show that the use of modern heat-recovery technologies for gas-fired boiler plants with the complex use of recycled heat for heating boiler water, water of CWP systems and combustion air decrease the formation of nitrogen oxides $\Delta C_{\mathrm{NOx}}$ to $60 \%$ due to the suppression of their formation in the combustion area the boiler. The use of this technology also ensures the reduction of harmful emissions from boilers by $10.8-17.5 \%$ due to a corresponding decrease in fuel consumption due to the beneficial use of the recovery heat of the exhaust-gases of the boiler.

\section{References}

1. N. Fialko, R. Navrodskaya, G. Gnedash, G. A. Presich, A. I. Stepanova, S. I. Shevchuk, International Scientific Journal for Alternative Energy and Ecology 15, 126-129 (2014)

2. R. Navrodskaya, N. Fialko, G. Gnedash, G. Sbrodova, Industrial Heat Engineering 39, 4, 69-75 (2017)

3. N. Fialko, A. Stepanova, R. Navrodska, J. Sherenkovsky, Promyshlennaya teplotekhnika 36, 1 ,41-47 (2014)

4. N. Fialko, A. Stepanova, G. Presich, G. Gnedash, Promyshlennaya teplotekhnika 37, 4, 71-79 (2015) 
5. L. Jia, X. F. Peng, Y. Yan, Int. J. Heat Mass Transfer 44, 4257-4265 (2001)

6. P. Rączka, K. Wójs, Rynek Energii 111, 87-92 (2014)

7. A. I. Sigal, Thermal Engineering 12, 34-37 (2004)

8. E. N. Bukharkin, Industrial Power Engineering 6, 40-42 (2004)

9. Y. M. Dashevskiy, B. Novikov, L. R. Khasanov-Agayev, Thermal Engineering 4, 61-63 (1991)

10. N. M. Fialko, R. A. Navrodskaya, S. I. Shevchuk, G. A. Presich, G. A. Gnedash, O. Glushak, Modern Science: Researches, Ideas, Results, Technologies 2, 15, 13-17 (2014)

11. V. V. Mitor, Thermal calculation of boiler units (Normative method, Ekolit, 296, 2011)

12. N. M. Fialko, V. I. Gomon, R. A. Navrodskaia, V. G. Prokopov, G. A. Presich, Promyshlennaia teplotekhnika 22, 2, 49-53 (200) 